\title{
Pretreatment but not subsequent coincubation with midazolam reduces the cytotoxicity of temozolomide in neuroblastoma cells
}

\author{
Sebastian Braun*, Inge Bauer, Benedikt Pannen and Robert Werdehausen
}

\begin{abstract}
Background: Temozolomide (TMZ) induces a G2/M cell cycle arrest and is used for treatment of paediatric tumours, especially neuroblastomas. Patients treated with TMZ frequently receive midazolam for sedation prior to surgery and other interventions. Previous studies suggested both cytoprotective and apoptosis-inducing properties of midazolam. Therefore, the impact of midazolam on TMZ-induced cytotoxicity was investigated in vitro.

Methods: Human neuroblastoma cells were incubated with midazolam alone, as a pretreatment prior to incubation with TMZ or a coincubation of both. Cell viability and proliferation was analysed (XTT and BrdU assay) after $24 \mathrm{~h}$ and flowcytometric cell cycle analysis was performed after 24 and $48 \mathrm{~h}$.

Results: Midazolam alone increased cell viability at lower concentrations $(2,4,8,16 \mu \mathrm{M})$, whereas higher concentrations $(128,256,512 \mu \mathrm{M})$ reduced cell viability. Pretreatment with midazolam $6 \mathrm{~h}$ prior to TMZ incubation reduced cytotoxic effects $\left(I C_{25} 1005 \pm 197 \mu \mathrm{M} ; I_{50} 1676 \pm 557 \mu \mathrm{M} ; P<0.05\right)$ compared to incubation with TMZ alone $\left(I_{25} 449 \pm 304 \mu \mathrm{M}\right.$; $\left.I_{50} 925 \pm 196 \mu \mathrm{M}\right)$ and reduced the antiproliferative effect of TMZ $(1000 \mu \mathrm{M})$ by $43.9 \%(P<0.05)$. In contrast, cytotoxic effects of TMZ were increased $\left(I_{75} 1175 \pm 221 \mu \mathrm{M}\right.$ vs. $\left.2764 \pm 307 \mu \mathrm{M} ; P<0.05\right)$ when midazolam pretreatment was followed by coincubation of midazolam and TMZ. Cell cycle analysis revealed increased fractions of cells in G2/M phase after TMZ treatment (100 $\mu \mathrm{M} ; 48 \mathrm{~h}$ ), irrespective of midazolam pretreatment.

Conclusion: Midazolam causes a hormetic dose-response relationship in human neuroblastoma cells. Pretreatment with midazolam reduces the cytotoxic and antiproliferative effects of TMZ without interfering with G2/M cell cycle arrest. In contrast, subsequent midazolam coincubation increases overall cytotoxicity.
\end{abstract}

Keywords: Temozolomide, Midazolam, Cytotoxicity, Hormesis, Cell cycle

\section{Background}

In the past decade, the relevance of temozolomide (TMZ), a DNA-methylating agent, for the treatment of paediatric solid tumours, especially neuroblastomas, has been elucidated [1-6]. There is evidence, that even relapsed or refractory tumours respond to TMZ alone or in combination with other cytostatic agents $[1-3,7]$. TMZ acts as a prodrug, which is spontaneously converted to the cytotoxic compound 5-(3-methyltriazen-1-yl) imidazole4-carbozamide (MTIC) and alkylates guanine in genomic DNA at position $O^{6}$ with subsequent impaired DNArepair and G2/M arrest [8]. Reduction of the cytotoxic

\footnotetext{
* Correspondence: brauns@uni-duesseldorf.de

Department of Anaesthesiology, University Hospital Düsseldorf, Moorenstr. 5, 40225 Düsseldorf, Germany
}

effect of TMZ by concomitant medication might reduce the effectiveness of anticancer regimen.

Midazolam is one of the most common sedatives for paediatric premedication $[9,10]$ and procedures that require temporary sedation (e.g. imaging) and has been reported recently the be among the 20 most often utilised medications in oncology patients associated with exert apoptosis-inducing properties, which are mediated by the mitochondrial pathway in neuroblastoma cells and primary rat neurons [12], while other modes of cytotoxicity were reported to be predominant in other human cell types [13]. Whereas high concentrations of midazolam $(>50 \mu \mathrm{M})$ induce apoptosis in a large fraction of neuroblastoma cells and primary rat neurons, low 
concentrations of midazolam $(5-10 \mu \mathrm{M})$ produce a slight increase of cell viability in primary rat neurons [12]. This effect has not been investigated in neuroblastoma cells so far. Thus, the influence of low concentrations of midazolam on cell viability in this cell line remains unknown. The increase of cell viability might counteract the cytotoxic effect of chemotherapeutics like TMZ and contribute to a reduced anticancer activity of these agents. Furthermore, no data are available, whether midazolam is able to modify the cell cycle of neuroblastoma cells, especially in regard to the TMZ-induced G2/M arrest.

We hypothesised, that midazolam at low concentrations increases cell viability, leading to a reduced toxicity of the anticancer agent TMZ by altering the cell cycle. A viability assay (XTT) was performed to evaluate the effect and toxicity of increasing concentrations of midazolam and TMZ. Additionally, a bromodeoxyuridinebased proliferation assay (BrdU) was used to estimate the effect of midazolam to the antiproliferative effect of temozolomide. The toxicity of $\mathrm{TMZ}\left(\mathrm{IC}_{25}, \mathrm{IC}_{50}\right.$ and $\left.\mathrm{IC}_{75}\right)$ after pretreatment and comedication with midazolam $(16 \mu \mathrm{M})$ was investigated and cell cycle analysis was performed to elucidate the effect of midazolam on the primary mode-of-action of TMZ.

\section{Methods}

\section{Materials and reagents}

Roswell Park Memorial Institute 1640 medium (RPMI) with and without phenol red and trypsin/EDTA (0.05\%/ $0.02 \%)$ were purchased from PAN-Biotech (Aidenbach, Germany). Penicillin and streptomycin were obtained from PAA Cell Culture Company (Cambridge, UK). $\mathrm{NaCl}, \mathrm{KCl}$, $\mathrm{KH}_{2} \mathrm{PO}_{4}$ and fetal calf serum were obtained from Merck (Darmstadt, Germany). Ethanol was obtained from Carl Roth $\mathrm{GmbH}$ (Karlsruhe, Germany). $\mathrm{Na}_{2} \mathrm{HPO}_{4}, \mathrm{DMSO}$, EDTA, propidium iodide, phenazine methosulfate, TMZ and staurosporine were purchased from Sigma-Aldrich (St. Louis, MO, USA). Preservative-free midazolam was obtained from ratiopharm GmbH (Ulm, Germany). 2,3Bis-(2-methoxy-4-nitro-5-sulfophenyl)-2H-tetrazolium-5carboxanilide (XTT) sodium salt was obtained from AppliChem GmbH (Darmstadt, Germany).

\section{Cell culture}

Human neuroblastoma cells (SHEP) (characterised in $[14,15])$ were cultured in RPMI medium, supplemented with $10 \%$ heat-inactivated fetal calf serum, 2 mM L-glutamine, $50 \mathrm{U} \mathrm{mL}^{-1}$ penicillin and $50 \mu \mathrm{g} \mathrm{mL}^{-1}$ streptomycin. Cells were cultured at $37{ }^{\circ} \mathrm{C}$ in a humidified $5 \%$ carbon dioxide atmosphere.

\section{Cell treatment and experimental setup}

Cell viability was assessed using the XTT assay after the following treatments: 1 : increasing concentrations of midazolam for $24 \mathrm{~h}(0,1,2,4,8,16,32,64,128,256$, $512 \mu \mathrm{M})$; 2: increasing concentrations of TMZ for $24 \mathrm{~h}$ (control, 10, 30, 100, 300, 1000 and $2000 \mu \mathrm{M}$ ); 3: increasing concentrations of TMZ for $24 \mathrm{~h}$ after pretreatment with midazolam $16 \mu \mathrm{M}$ for $6 \mathrm{~h}$; 4: increasing concentrations of TMZ for $24 \mathrm{~h}$ after pretreatment with midazolam $16 \mu \mathrm{M}$ for $6 \mathrm{~h}$ or pretreatment + coincubation for $24 \mathrm{~h}$.

Cell cycle analysis using the Nicoletti assay [16] was performed after incubation with 1.: $\operatorname{TMZ}(0,10,100$, $1000 \mu \mathrm{M})$ for $24 \mathrm{~h}, 2 .:$ pretreatment with midazolam $16 \mu \mathrm{M}$ for $6 \mathrm{~h}$ with subsequent incubation with TMZ $(0$, $10,100,1000 \mu \mathrm{M})$ for $24 \mathrm{~h}, 3 .: \operatorname{TMZ}(0,10,100$, $1000 \mu \mathrm{M})$ for $48 \mathrm{~h}, 4 .:$ pretreatment with midazolam $16 \mu \mathrm{M}$ for $6 \mathrm{~h}$ with subsequent incubation with TMZ $(0$, $10,100,1000 \mu \mathrm{M})$ for $48 \mathrm{~h}$.

\section{Analysis of cell viability}

The XTT assay was used for measurement of cell viability. Briefly, XTT (2,3-Bis(2-methoxy-4-nitro-5-sulfonyl)-2Htetrazolium-5-carboxanilide inner salt) is metabolised to a coloured formazan dye in vital cells by mitochondrial dehydrogenase. Due to the fact, that only vital cells are capable to metabolise XTT, the amount of produced formazan dye is indicative for the fraction of vital cells. To evaluate cell viability, $100 \mu \mathrm{l}$ of cell suspension with a cell concentration of $10^{5} \mathrm{ml}^{-1}$ per well were incubated overnight in a 96-well plate. Each well was washed with PBS to remove unattached cells and refilled with $200 \mu \mathrm{l}$ colourless medium (RPMI without phenol red), supplemented with different concentrations of midazolam and TMZ alone or in combination. After $24 \mathrm{~h}, 100 \mu \mathrm{l}$ cell culture supernatant were removed from each well and $50 \mu \mathrm{l}$ of the dye solution were added, containing XTT $\left(1 \mathrm{mg} \mathrm{ml}^{-1}\right)$ and phenazine methosulfate $(50 \mu \mathrm{M})$. After gentle mixing of the samples, the plate was incubated for $120 \mathrm{~min}$ at $37^{\circ} \mathrm{C}$. Subsequently, samples were measured spectrophotometrically at $540 \mathrm{~nm}$.

\section{Analysis of cell proliferation}

A colorimetric immunoassay was used to quantify cell proliferation. Shortly, during DNA synthesis, proliferating cells integrate the thymidine analogue 5-bromo-2'deoxyuridine (BrdU) instead of thymidine. Following denaturation, a peroxidase-conjugated antibody binds to newly incorporated BrdU. After a specific substrate reaction with tetramethylbenzidine, spectrophotometrical measurement of absorbance indicates the extent of newly synthesised DNA as a parameter of proliferation. In detail, $200 \mu \mathrm{l}$ of a cell suspension containing $1 \times 10^{4}$ $\mathrm{ml}^{-1}$ cells were incubated in each well of a 96-well plate overnight to ensure adherence and logarithmic growth. Subsequent incubation with the investigated substances was followed by fixing the cells and denaturation. 
Incubation with anti-BrdU-peroxidase conjugated specific antibodies to BrdU. After a washing step with $200 \mu \mathrm{l}$ PBS and subsequent addition of $100 \mu \mathrm{l}$ substrate solution containing tetramethylbenzidine, absorbance was measured at $370 \mathrm{~nm}$ and $492 \mathrm{~nm}$ (read-out absorbance $=$ absorbance $_{370 \mathrm{~nm}}-$ absorbance $\left._{492 \mathrm{~nm}}\right)$.

\section{Cell cycle analysis}

Cell staining with propidium iodide allows quantifying the amount of cellular DNA, which indicates the phase of the cell cycle. After permeabilisation and staining, the quantity of cellular DNA is analysed by flow cytometric analysis, using the intensity of fluorescence of the stained DNA. Modifications of the cell cycle by drugs like TMZ are indicated by a change of the flow cytometric patterns [16].

For cell cycle analysis, $2 \mathrm{ml}$ of cell suspension were incubated with a concentration of $0.5 \times 10^{5}$ cells ml $\mathrm{ml}^{-1}$ overnight to reach adherence. Medium was replaced and supplemented with the investigated substance. After the defined time period, supernatant was harvested and adherent cells were detached with trypsin/EDTA $0.05 \%$ / $0.02 \%$ at $37{ }^{\circ} \mathrm{C}$ and added to the supernatant. After centrifugation $\left(1600 \mathrm{rpm}, 5 \mathrm{~min}, 21{ }^{\circ} \mathrm{C}\right)$, the supernatant was removed and cells were washed with $1 \mathrm{ml}$ of PBS. Subsequently, cells were incubated with $250 \mu$ l Nicoletti buffer (containing sodium citrate dihydrate $0.1 \%$, Triton $\mathrm{X}-1000.1 \%$ and propidium iodide $50 \mu \mathrm{g} \mathrm{ml}^{-1}$ ) and kept on ice until completion of flow cytometric analysis.

\section{Statistics}

Results are expressed as means $\pm \mathrm{SD}$. All calculations were made with GraphPad Prism version 5.03 for Windows (GraphPad Software, San Diego, CA, USA). The values for drug concentrations leading to $25 \%$, $50 \%$ or $75 \%$ reduction of cell viability $\left(\mathrm{IC}_{25}, \mathrm{IC}_{50}\right.$ and $\mathrm{IC}_{75}$, respectively) and the zero equivalent point (ZEP) were obtained from nonlinear regression analysis for bellshaped dose-response relationships. Statistical analysis was performed by means of Student's $t$-Test or one-way analysis of variance (ANOVA) with Bonferroni post hoc test. $P<0.05$ was considered significant.

\section{Results}

\section{Cell viability after incubation with different} concentrations of midazolam

To evaluate the impact of midazolam on the viability of neuroblastoma cells, XTT assay was performed after incubation for $24 \mathrm{~h}$ with increasing concentrations of midazolam. In particular with regard to low concentrations of midazolam, small increments of concentrations were selected.

Midazolam increased cell viability in neuroblastoma cells at the lower concentrations used $(2,4,8$ and $16 \mu \mathrm{M})$, whereas higher concentrations (128, 256 and $512 \mu \mathrm{M})$ led to a profound decline of cell viability (Figure 1). Thus, midazolam caused a hormetic response with regard to cytotoxicity, characterised by a low-concentration stimulation and a high-concentration inhibition. The "Zero Equivalent Point" (ZEP) describes the point of reversal of response and defines the concentration of midazolam, which is characterised by the transition from protective to toxic effects [17]. The ZEP of midazolam was $79.4 \mu \mathrm{M}$. The $\mathrm{IC}_{50}$ of midazolam in the investigated neuroblastoma cell line was $226.9 \pm 13.2 \mu \mathrm{M}$.

Impact of pretreatment and pretreatment + coincubation of midazolam to the $\mathrm{IC}_{25}, \mathrm{IC}_{50}$ and $\mathrm{IC}_{75}$ of temozolomide The dose-response of TMZ was investigated without midazolam and after pretreatment $(6 \mathrm{~h}$ prior to TMZ incubation) or pretreatment followed by coincubation ( $6 \mathrm{~h}$ prior to TMZ incubation and subsequent coincubation for $24 \mathrm{~h}$ ) with midazolam $(16 \mu \mathrm{M})$ (Fig. 2). Pretreatment with midazolam $(16 \mu \mathrm{M})$ increased both the $\mathrm{IC}_{25}$ $(1005 \pm 197 \mu \mathrm{M}$ vs. $449 \pm 304 \mu \mathrm{M} ; P<0.05$, Fig. 3a) and $\mathrm{IC}_{50}(1676 \pm 557 \mu \mathrm{M}$ vs. $925 \pm 196 \mu \mathrm{M} ; P<0.05$, Fig. $3 \mathrm{~b})$.

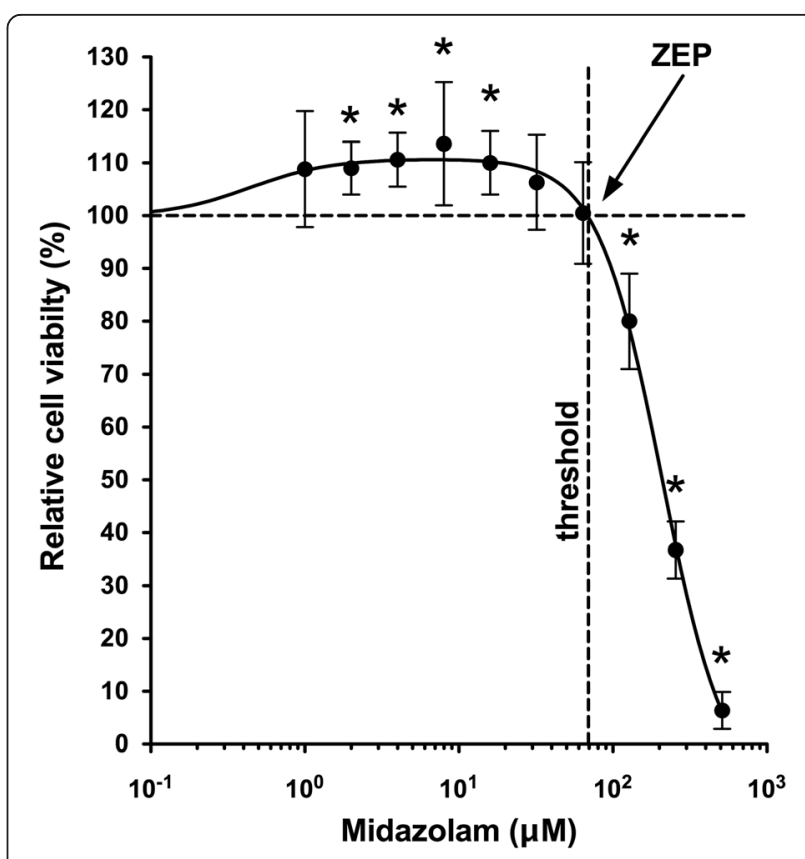

Fig. 1 Midazolam-induced hormesis and toxicity in neuroblastoma (SHEP) cells. Cell viability of neuroblastoma (SHEP) cells was measured with the XTT assay to investigate cell viability after incubation for $24 \mathrm{~h}$ with increasing concentrations of midazolam. The "Zero Equivalent Point" (ZEP) describes the point of reversal of response and defines the concentration of midazolam, which is characterised by the transition from protective to toxic effects [17]. The ZEP of midazolam was $79.4 \mu \mathrm{M}$. A significant increase of cell viability in comparison to control was detected after incubation with 2, 4, 8, and $16 \mu \mathrm{M}$, whereas a significant decline was measured after incubation with 128,256 and $512 \mu \mathrm{M}$ midazolam $\left(n=8 ;{ }^{*}=P<0.05\right.$ compared to control $(0 \mu \mathrm{M}$ midazolam); data are expressed as mean \pm SD) 


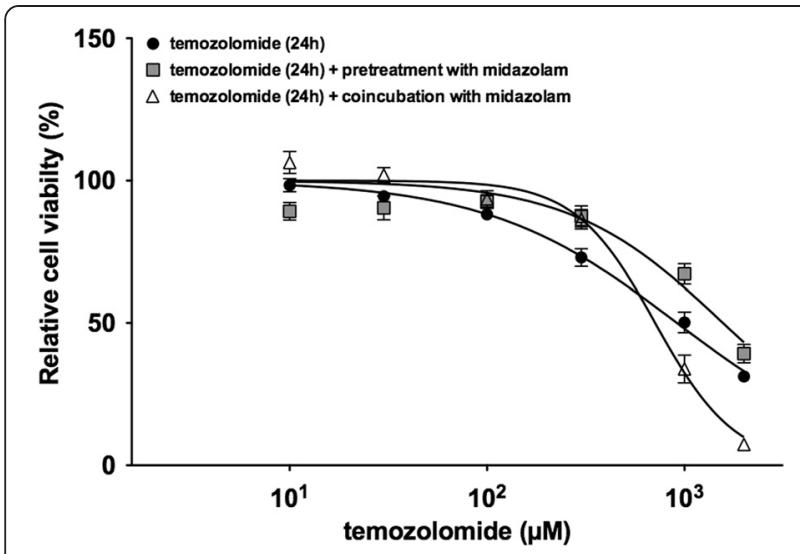

Fig. 2 Effect of pretreatment and coincubation with midazolam to temozolomide induced toxicity. Cell viability of neuroblastoma (SHEP) cells was measured using the XTT assay after incubation with increasing concentrations of temozolomide (24 h). Black circles: relative cell viability after incubation with TMZ (10, 30, 100, 300, 1000, $2000 \mu \mathrm{M})$; greys squares: pretreatment with midazolam $(16 \mu \mathrm{M})$ for $6 \mathrm{~h}$ with subsequent incubation with increasing concentrations of temozolomide; white triangles: pretreatment with midazolam (16 $\mu \mathrm{M})$ followed by coincubation with temozolomide ( 24 h) $(n=5$; data are expressed as mean \pm SD)

In contrast, the $\mathrm{IC}_{75}$ of $\mathrm{TMZ}$ was unaffected by midazolam pretreatment (Fig. 3c).

Midazolam pretreatment followed by coincubation with TMZ did not change the $\mathrm{IC}_{25}$ and $\mathrm{IC}_{50}$ of $\mathrm{TMZ}$, while the $\mathrm{IC}_{75}$ of $\mathrm{TMZ}$ was decreased significantly ( $\mathrm{IC}_{75} 1175 \pm$ $221 \mu \mathrm{M}$ vs. $2764 \pm 307 \mu \mathrm{M} ; P<0.05)$, indicating an amplification of the TMZ-induced cytotoxicity (Fig. 3a-c).

\section{The influence of pretreatment and pretreatment +} coincubation of midazolam to the antiproliferative effect of temozolomide

The proliferation rate of neuroblastoma (SHEP) cells was measured using the BrdU-assay after incubation with increasing concentrations of TMZ with and without midazolam. Pretreatment with midazolam $6 \mathrm{~h}$ prior to TMZ exposure significantly attenuated the antiproliferative effect of TMZ $1000 \mu \mathrm{M}$ by $43.9 \%(P<0.05$; Fig. 4), whereas midazolam pretreatment for $6 \mathrm{~h}$ with further coincubation for $24 \mathrm{~h}$ with TMZ did not alter the antiproliferative effect of TMZ (Fig. 4).

\section{Affection of the cell cycle after incubation with different concentrations of temozolomide with and without pretreatment of midazolam}

The flow cytometric measurement of propidium iodidestained DNA enables to discriminate different contents of intracellular DNA in order to specify the cell cycle. We investigated the impact of a wide range of concentrations of TMZ $(10,100,1000 \mu \mathrm{M})$ on the fraction of cells with a diploid DNA content indicating the G2/M phase. No difference was detected with or without pretreatment of midazolam $(16 \mu \mathrm{M})$ after incubation for $24 \mathrm{~h}$. After $48 \mathrm{~h}$, the fraction of cells being in the G2/M phase was significantly increased after treatment with TMZ (100 $\mu \mathrm{M})$, while pretreatment with midazolam $(16 \mu \mathrm{M})$ did not modify this effect (Figs. 5 and 6).

\section{Discussion}

In the present study, we investigated the dose-dependent effects of midazolam on cell viability in neuroblastoma (SHEP) cells and the impact of midazolam pretreatment and coapplication on the cytotoxicity and antiproliferative effects of TMZ. Furthermore, the effect on the main anti-cancer mechanism of TMZ, the G2/M arrest, was evaluated.

We revealed that midazolam alone induced a significant increase of cell viability with $2,4,8$ and $16 \mu \mathrm{M}$, whereas 128, 256 and $512 \mu \mathrm{M}$ of midazolam reduced cell viability $\left(\mathrm{IC}_{50}: 227 \mu \mathrm{M}\right)$. Transition from protective to toxic effects of midazolam was estimated to occur at 79.4 $\mu \mathrm{M}$. When administered as a pretreatment $6 \mathrm{~h}$ prior to TMZ exposure, midazolam at a stimulatory concentration of $16 \mu \mathrm{M}$ significantly increased the $\mathrm{IC}_{25}$ and $\mathrm{IC}_{50}$ of $\mathrm{TMZ}$, whereas the $\mathrm{IC}_{75}$ remained unaffected. Pretreatment followed by coincubation abolished this effect and lowered the $\mathrm{IC}_{75}$ of $\mathrm{TMZ}$ as a sign of additional toxicity. The antiproliferative effect of TMZ $(1000 \mu \mathrm{M})$ was significantly attenuated by pretreatment with
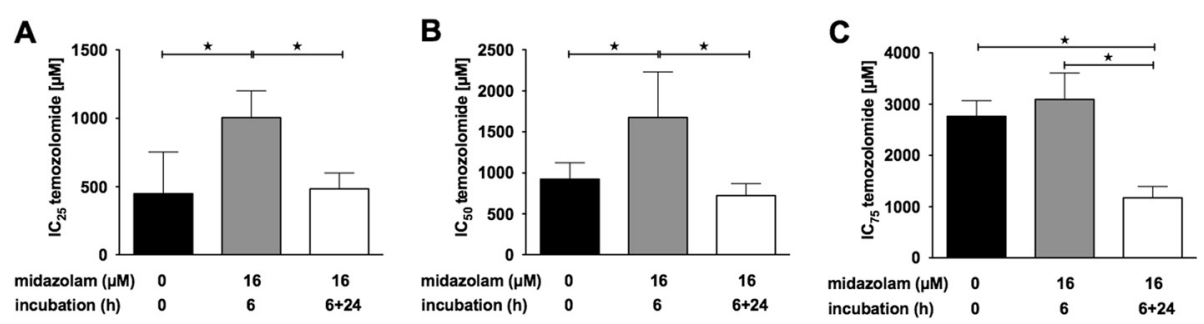

Fig. 3 Midazolam modifies the toxicity of temozolomide. The $I C_{25}, I C_{50}$ and $I C_{75}$ (Panel $\mathbf{a}, \mathbf{b}$, and $\mathbf{c}$, respectively) were calculated with nonlinear regression analysis. Whereas pretreatment without subsequent coincubation increased the $I_{25}$ and $I C_{50}$ of temozolomide, pretreatment followed by coincubation with midazolam did not alter the $I_{25} / I C_{50}$ of temozolomide. The $I C_{75}$ was significantly decreased after pretreatment followed by coincubation with midazolam, indicating an additive toxic effect $\left(n=5\right.$; data are expressed as mean $\pm \mathrm{SD}^{*}{ }^{*}=P<0.05$ 


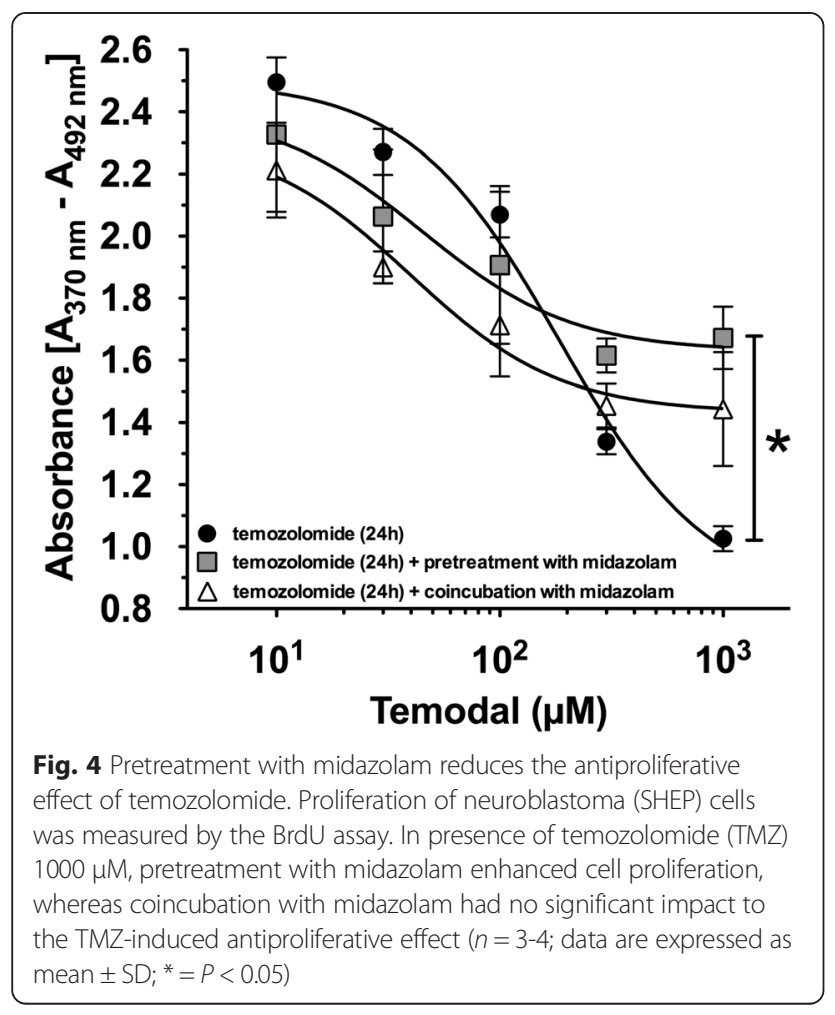

midazolam, whereas pretreatment followed by coincubation with midazolam had no impact. With view to cell cycle analysis, TMZ $(100 \mu \mathrm{M})$ increased the fraction of cells in G2/M phase after $48 \mathrm{~h}$. Pretreatment followed by coincubation with midazolam did not affect the G2/M arrest.

To date, data focusing on a pharmacologic interference between the sedative midazolam and the chemotherapeutic agent TMZ were lacking. Since neuroblastoma tumour cells are a common therapeutic target of TMZ in clinical practice, we chose an in vitro model of a human neuroblastoma cell line. Furthermore, the comparatively high incidence of this tumour in childhood increases the probability of midazolam being co-applied to TMZ, therefore possibly increasing clinical relevance of the supposed effect on the cytotoxic potency of TMZ. However, to mirror clinical practice and issues with an in vitro study has multiple limitations in particular with view to pharmacological parameters like half-life $\left(t_{1 / 2}\right)$, peak levels, renal and hepatic elimination and tissue concentration. Nevertheless, this study reveales first evidence, that midazolam ameliorates the cytotoxic effects of TMZ in neuroblastoma cells in vitro. The time period of pretreatment with midazolam was $6 \mathrm{~h}$ in our study and therefore reflects an increased $t_{1 / 2}$ of midazolam in children and infants compared to adults [18]. As hepatic or renal impairment and mode of administration strongly alters $t_{1 / 2}$, a single time period of pretreatment might not be sufficient to investigate a so far unknown effect. Further evaluation is necessary to specify the pharmacokinetic impact on the cytoprotective effects of midazolam. One of the most frequently discussed criticisms of pharmacologic in vitro studies involves the concentrations of the applied substances, as they frequently differ from plasma or tissue concentrations used in clinical practice. In our study, we used a broad spectrum of concentrations of midazolam and temozolomide. The logarithmic increase of the applied concentrations enabled us to discriminate small effects of low concentrations of midazolam and the evaluation of the $\mathrm{IC}_{25}, \mathrm{IC}_{50}$ and $\mathrm{IC}_{75}$ of temozolomide. The concentration of midazolam $(16 \mu \mathrm{M})$ used for pretreatment in our study was within the concentration range reached after premedication and continuous sedation $(0.3-23 \mu \mathrm{M})$ as reported previously [19-21]. Nevertheless, a comparison of in vitro and in vivo concentrations of midazolam remains somewhat artificial. Three concentrations of TMZ were tested with view to an expected G2/M-arrest. Solely $100 \mu \mathrm{M}$ of TMZ induced this effect after $48 \mathrm{~h}$. This concentration is comparable to plasma levels of patients treated with temozolomide ( $72 \mu \mathrm{M})$, but is 10 -fold higher compared to levels of TMZ in the cerebrospinal fluid of these patients [22]. However, effective concentrations in targeted tissues remain unclear and further investigations may be required to characterise the impact of TMZ at different tissue concentrations and time periods of treatment.

The observed increase of cell viability in a neuroblastoma cell line after incubation with low concentrations of midazolam is a counterintuitive finding. Sedatives like midazolam are known as potentially harmful agents especially for neuronal cells with apoptosis-inducing properties at high concentrations, as described above. Previously, Chong and colleagues had shown that midazolam is capable of protecting against reactive oxygen species (ROS) induced cell death in B35 neuroblastoma cells [23]. They reported that pretreatment with midazolam leads to protection against ROS by induction of Akt phosphorylation after activation of phosphoinositol-3kinase (PI3K). Interestingly, the pretreatment with midazolam was comparable to our study design with regard to treatment duration $(8 \mathrm{~h})$ and applied concentrations of midazolam (5 and $10 \mu \mathrm{M})$. While their data indicate that incubation with midazolam alone induces Akt phosphorylation, it remains unknown, whether this leads to increased cell viability also in the absence of ROS and, if so, this effect could be abolished by blocking the phosphoinositol-3-kinase. Thus, it remains an open question if Akt activation is involved in the viability enhancing effect of midazolam in our present study. Another study revealed, that midazolam $(10 \mu \mathrm{M})$ attenuates the antiproliferative effect of glucose oxygen deprivation (GOD) by modulating the profile of proand antiapoptotic proteins in astrocytes [24]. As in the study by Chong et al. [23] however, again no data were 

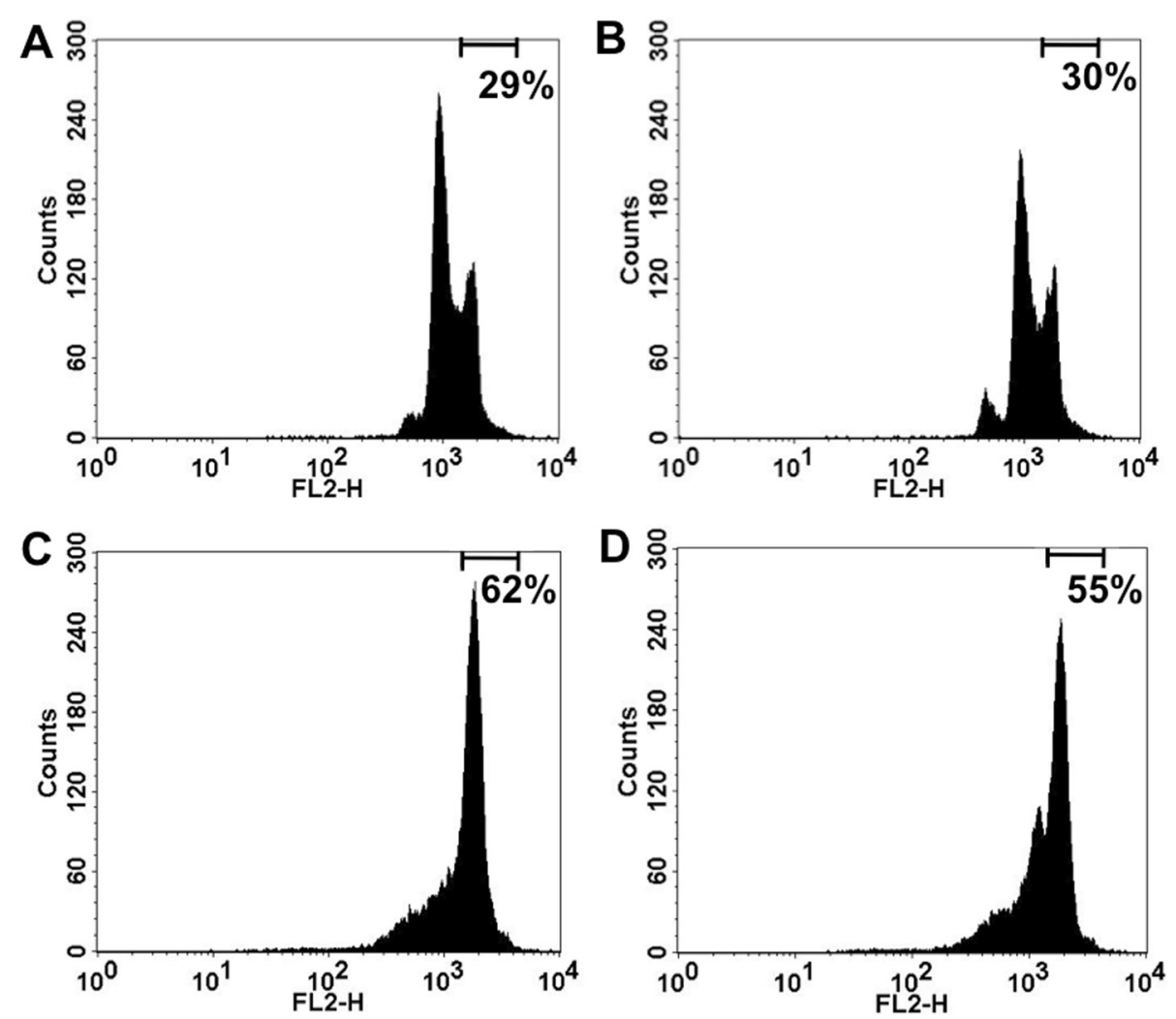

Fig. 5 Analysis of the G2/M phase after incubation with temozolomide. Representative registrations of the flow cytometric analysis of neuroblastoma (SHEP) cells after staining with propidium iodide (48 h). The percentage of cells with a diploid DNA content indicating the G2/M phase is indicated in the upper right corner. Panel a control; Panel $\mathbf{b}$ temozolomide $10 \mu \mathrm{M}$; Panel $\mathbf{c}$ temozolomide $100 \mu \mathrm{M}$, Panel $\mathbf{d}$ temozolomide $100 \mu \mathrm{M}$ with pretreatment with midazolam $(16 \mu \mathrm{M} ; 6 \mathrm{~h})$

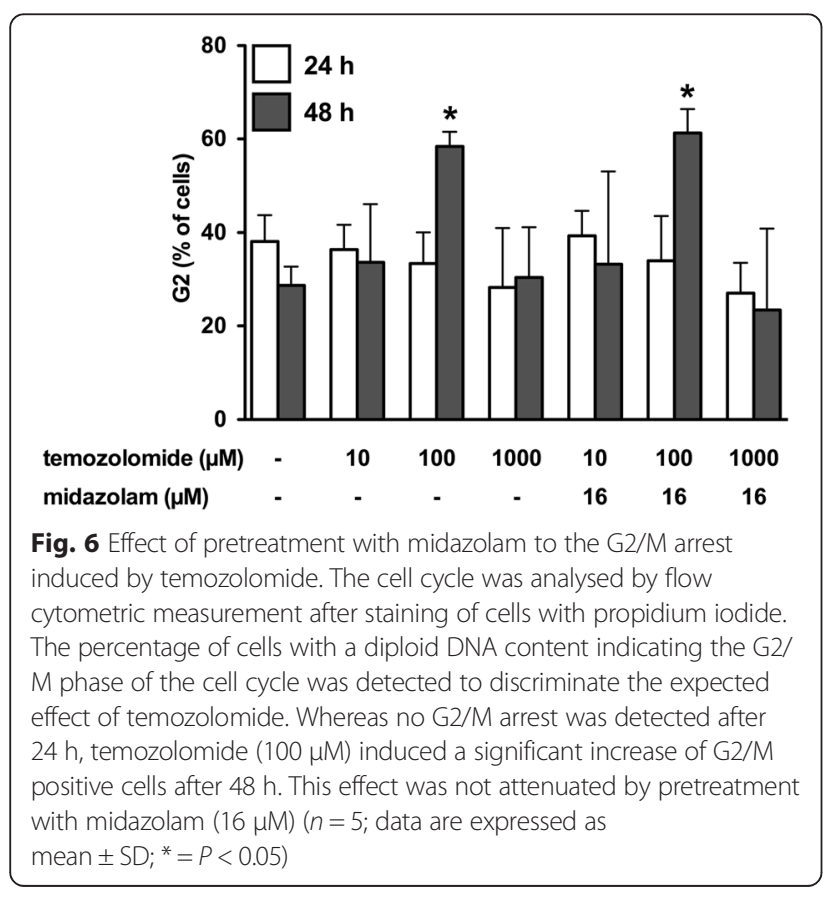

presented regarding the impact of midazolam alone on cell viability. Guo and co-workers reported cytoprotective effects of midazolam $(0.4-40 \mu \mathrm{M})$ due to stimulation of steroidogenesis after corticosterone-induced toxicity in rat astrocytes [25]. Midazolam induced the release of pregnenolone and progesterone into the medium, while inhibition of pregnenolone metabolism abolished the protective effect of midazolam. To summarise, Akt phosporylation, modulation of apoptosis-regulating proteins and stimulation of steroidogenesis have been associated with cytoprotective effects of midazolam, although a positive effect like an increase of cell proliferation and viability in the absence of a toxic stimulus has not been reported. Therefore, the potential role of these mechanisms for the protective properties described in our study remains unclear. Whereas only low concentrations of midazolam were investigated in those studies, we evaluated a broader concentration range. This approach enabled us to observe a dose-response relationship phenomenon for midazolam, which is known as hormesis. Hormesis is a toxicological concept, which is defined by Kendig et al. as a "dose-response relationship for a single endpoint that is characterised by reversal of response between low and high doses of chemicals, 
biological molecules, physical stressors, or any other initiators of a response" [17]. We observed the typical inverted $\mathrm{u}$-shaped dose response curve, which indicates a hormetic response of neuroblastoma cells after incubation with midazolam and confirms a dose-dependent stimulatory and inhibitory effect of this agent. There is considerable evidence, that many endogenous mediators, drugs and toxines can induce hormesis via receptor- and cell signaling mechanisms, e.g. the PI3K, ERK1/2 and p38-pathway [26]. Further investigations are required to determine which mechanisms are involved in the hormetic response induced by midazolam. In contrast, TMZ did not induce a hormetic effect in neuroblastoma cells in our study, which is in line with previous results. Previous studies investigating concentrations of $0.1-10 \mu \mathrm{M}$ TMZ revealed an anti-cancer effect without any evidence for hormesis [27-29]. Another, more methodological reason could be the lack of very subtle graduation of low dose concentrations. However, with view to the $\mathrm{IC}_{50}$ of both agents, the range of stimulatory concentrations of midazolam (1.7-14 \% of $\left.\mathrm{IC}_{50}\right)$ was comparable with analysed concentrations of TMZ, which did not induce any stimulatory effect. Taken together, there is no evidence that TMZ is involved in effects based on hormesis [22]. Interestingly, the time course of midazolam application has a major impact on the protective effect. Pretreatment induced a significant increase of the $\mathrm{IC}_{25}$ and $\mathrm{IC}_{50}$ of $\mathrm{TMZ}$, whereas pretreatment with subsequent coincubation amplified the toxicity at high concentrations (reduced $\mathrm{IC}_{75}$ ) of TMZ. Taken together, these findings suggest that the attenuating properties of low-dose midazolam for TMZ-induced cytotoxicity are dependent on the timing of exposure and the magnitude of the subsequent toxic stimulus.

Further aspects of TMZ-induced toxicity were revealed by the proliferation assay (BrdU), which indicated dosedependent inhibition of neuroblastoma cell proliferation as expected. Pretreatment with midazolam attenuated the antiproliferative effect of TMZ $(1000 \mu \mathrm{M})$, whereas pretreatment with subsequent coincubation had no significant impact on cell proliferation. Thus, pretreatment with midazolam is capable to affect cell characteristics even followed by exposure to high TMZ concentrations.

As the anticancer properties of TMZ are primarily related to the induction of a G2 arrest of the cells, we investigated the influence of TMZ with and without midazolam on the cell cycle. Surprisingly, $24 \mathrm{~h}$ of incubation with TMZ $(10,100,1000 \mu \mathrm{M})$ did not lead to a significant increase of G2/M-positive cells. The detection of an effect on the fraction of G2/M-positive cells after incubation with TMZ might require an appropriate amount of cell division, which is only reached after $48 \mathrm{~h}$. This hypothesis is based on the result of cell cycle analysis after $48 \mathrm{~h}$, as TMZ $(100 \mu \mathrm{M})$ increased the fraction of G2/M-positive cells significantly. Pretreatment with midazolam did not alter this result, suggesting a different mode-of-action for midazolam-induced cytoprotection. Although midazolam pretreatment does not seem to influence the specific anticancer mechanisms of TMZ, the increase of mitochondrial activity, as indicated by XTT assay analysis, may contribute to the cytoprotective properties of midazolam. This fits well to the detected hormetic effect of midazolam, as hormesis is generally understood not to be based on a single mechanistic pathway, but rather reflects a complex pattern of cellular reactions to an unspecific sublethal stimulus.

\section{Conclusion}

In this in vitro study in neuroblastoma (SHEP) cells, midazolam induced a biphasic action with increased cell viability after incubation at low concentrations, whereas high concentrations led to a profound decline in cell viability. Pretreatment with low concentrations of midazolam attenuated the toxic effect of TMZ, whereas pretreatment followed by coincubation had no cytoprotective effect. High concentrations of TMZ abolished the cytoprotection of pretreatment with midazolam. Coincubation with midazolam aggravated the toxicity of highdose TMZ. The antiproliferative effect of TMZ was attenuated by pretreatment with midazolam. The TMZinduced G2/M arrest was detected after $48 \mathrm{~h}$ of incubation and was not attenuated by pretreatment with midazolam. Our findings may indicate the possibility of reduced anticancer effects of TMZ in patients pretreated with midazolam and therefore justify further investigations into the interaction of chemotherapeutic agents with frequently used comedications like midazolam and other agents with cytotoxic potential.

\section{Abbreviations}

BrdU: Bromodeoxyuridine; DMSO: Dimethyl sulfoxide; DNA: Deoxyribonucleic acid; EDTA: Ethylenediaminetetraacetic acid; GOD: Glucose oxygen deprivation; IC: Inhibitory concentration; ROS: Reactive oxygen species; RPMI: Roswell Park Memorial Institute; TMZ: Temozolomide; XTT: 2,3-Bis(2-methoxy-4-nitro-5-sulfonyl)2H-tetrazolium-5-carboxanilide; ZEP: Zero Equivalent Point.

\section{Competing interests}

The authors confirm that they have no conflict of interest. Support was provided solely from institutional sources.

\section{Authors' contributions}

SB initiated and coordinated this study, participated in the entire laboratory work and helped to prepare and draft the manuscript. IB was involved in the study design, laboratory work, statistical analysis and helped to draft the manuscript. BP participated in the coordination of the study, helped to draft the manuscript and revised the manuscript critically. RW was involved in the conception of the study, the entire laboratory work, especially the cell cycle analysis and the proliferation assay, the statistical analysis and helped to draft the manuscript. All authors read and approved the final manuscript.

Authors' information

All authors are members of the Department of Anaesthesiology, University Hospital Düsseldorf. 


\section{Acknowledgements}

We gratefully thank Dr. Pablo E. Verde, Coordination Centre for Clinical Studies, University Hospital Düsseldorf, for statistical review and support and Claudia Dohle and Nadine Lottmann for technical assistance.

Received: 17 July 2015 Accepted: 8 October 2015

Published online: 17 October 2015

\section{References}

1. Armstrong AE, Dargart J, Reichek J, Walterhouse DO, Matossian D, Cohn RA, et al. Irinotecan and temozolomide for treatment of neuroblastoma in a patient with renal failure on hemodialysis. Pediatr Blood Cancer. 2014:61:949-50

2. Bagatell $R$, London WB, Wagner LM, Voss SD, Stewart CF, Maris JM, et al. Phase II study of irinotecan and temozolomide in children with relapsed or refractory neuroblastoma: a Children's Oncology Group study. J Clin Oncol. 2011;29:208-13.

3. Bagatell R, Norris R, Ingle AM, Ahern C, Voss S, Fox E, et al. Phase 1 trial of temsirolimus in combination with irinotecan and temozolomide in children, adolescents and young adults with relapsed or refractory solid tumors: a Children's Oncology Group Study. Pediatr Blood Cancer. 2014;61:833-9.

4. De Sio L, Milano GM, Castellano A, Jenkner A, Fidani P, Dominici $C$, et al. Temozolomide in resistant or relapsed pediatric solid tumors. Pediatr Blood Cancer. 2006:47:30-6.

5. Grill J, Geoerger B, Gesner L, Perek D, Leblond P, Cañete A, et al. European Consortium Innovative Therapies for Children with Cancer (ITCC) and the European Society for Paediatric Oncology (SIOPE) brain tumor group: Phase II study of irinotecan in combination with temozolomide (TEMIRI) in children with recurrent or refractory medulloblastoma: a joint ITCC and SIOPE brain tumor study. Neuro Oncol. 2013;15:1236-43.

6. Middlemas DS, Stewart CF, Kirstein MN, Poquette C, Friedman HS, Houghton PJ, et al. Biochemical correlates of temozolomide sensitivity in pediatric solid tumor xenograft models. Clin Cancer Res. 2000;6:998-1007.

7. Rubie H, Chisholm J, Defachelles AS, Morland B, Munzer C, Valteau-Couanet D, et al. Société Françaisedes Cancers de l'Enfant, United Kingdom Children Cancer Study Group-New Agents Group Study: Phase II study of temozolomide in relapsed or refractory high-risk neuroblastoma: a joint Société Française des Cancers de l'Enfant and United Kingdom Children Cancer Study Group-New Agents Group Study. J Clin Oncol. 2006;24:5259-64.

8. Filippi-Chiela EC, Thomé MP, Bueno E, Silva MM, Pelegrini AL, Ledur PF, et al. Resveratrol abrogates the Temozolomide-induced $G 2$ arrest leading to mitotic catastrophe and reinforces the Temozolomide-induced senescence in glioma cells. BMC Cancer. 2013;13:147.

9. Kain ZN, Mayes LC, Bell C, Weisman S, Hofstadter MB, Rimar S. Premedication in the United States: a status report. Anesth Analg. 1997;84:427-32

10. Machata A-M, Willschke H, Kabon B, Kettner SC, Marhofer P. Propofol-based sedation regimen for infants and children undergoing ambulatory magnetic resonance imaging. Br J Anaesth. 2008;101:239-43.

11. Barrett JS, Patel D, Dombrowsky E, Bajaj G, Skolnik JM. Risk assessment of drug interaction potential and concomitant dosing pattern on targeted toxicities in pediatric cancer patients. AAPS J. 2013;15:775-86.

12. Stevens MF, Werdehausen R, Gaza N, Hermanns H, Kremer D, Bauer I, et al. Midazolam activates the intrinsic pathway of apoptosis independent of benzodiazepine and death receptor signaling. Reg Anesth Pain Med. 2011;36:343-9.

13. Ohno S, Kobayashi K, Uchida S, Amano O, Sakagami H, Nagasaka H. Cytotoxicity and type of cell death induced by midazolam in human oral normal and tumor cells. Anticancer Res. 2012;32:4737-47.

14. Biedler JL, Helson L, Spengler BA. Morphology and growth, tumorigenicity, and cytogenetics of human neuroblastoma cells in continuous culture. Cancer Res. 1973;33:2643-52.

15. Fulda S, Susin SA, Kroemer G, Debatin KM. Molecular ordering of apoptosis induced by anticancer drugs in neuroblastoma cells. Cancer Res. 1998;58:4453-60.

16. Riccardi C, Nicoletti I. Analysis of apoptosis by propidium iodide staining and flow cytometry. Nat Protoc. 2006;1:1458-61.

17. Kendig EL, Le HH, Belcher SM. Defining hormesis: evaluation of a complex concentration response phenomenon. Int J Toxicol. 2010;29:235-46.

18. Pacifici GM. Clinical Pharmacology of Midazolam in Neonates and Children: Effect of Disease-A Review. Int J Pediatr. 2014;2014:309342.
19. Brosius KK, Bannister CF. Midazolam premedication in children: a comparison of two oral dosage formulations on sedation score and plasma midazolam levels. Anesth Analg. 2003;96:392-5. table of contents.

20. Hartwig S, Roth B, Theisohn M. Clinical experience with continuous intravenous sedation using midazolam and fentanyl in the paediatric intensive care unit. Eur J Pediatr. 1991:150:784-8.

21. Mulla H, McCormack P, Lawson G, Firmin RK, Upton DR. Pharmacokinetics of midazolam in neonates undergoing extracorporeal membrane oxygenation. Anesthesiology. 2003;99:275-82.

22. Ostermann S, Csajka C, Buclin T, Leyvraz S, Lejeune F, Decosterd LA, et al. Plasma and cerebrospinal fluid population pharmacokinetics of temozolomide in malignant glioma patients. Clin Cancer Res. 2004;10:3728-36.

23. Chong WS, Hyun CL, Park MK, Park JM, Song H-O, Park T, et al. Midazolam protects B35 neuroblastoma cells through Akt-phosphorylation in reactive oxygen species derived cellular injury. Korean J Anesthesiol. 2012;62:166-71.

24. Liu L, You Q, Tu Y, Li Q, Zheng L, Li X, et al. Midazolam inhibits the apoptosis of astrocytes induced by oxygen glucose deprivation via targeting JAK2-STAT3 signaling pathway. Cell Physiol Biochem. 2015;35:126-36

25. Guo W-Z, Miao Y-L, An L-N, Wang X-Y, Pan N-L, Ma Y-Q, et al. Midazolam provides cytoprotective effect during corticosterone-induced damages in rat astrocytes by stimulating steroidogenesis. Neurosci Lett. 2013;547:53-8.

26. Calabrese EJ. Hormetic mechanisms. Crit Rev Toxicol. 2013;43:580-606.

27. Jakubowicz-Gil J, Langner E, Badziul D, Wertel I, Rzeski W. Apoptosis induction in human glioblastoma multiforme T98G cells upon temozolomide and quercetin treatment. Tumour Biol. 2013:34:2367-78.

28. Jakubowicz-Gil J, Langner E, Rzeski W. Kinetic studies of the effects of Temodal and quercetin on astrocytoma cells. Pharmacol Rep. 2011;63:403-16.

29. Raymond E, Izbicka E, Soda H, Gerson SL, Dugan M, Von Hoff DD. Activity of temozolomide against human tumor colony-forming units. Clin Cancer Res. 1997;3:1769-74

\section{Submit your next manuscript to BioMed Central and take full advantage of:}

- Convenient online submission

- Thorough peer review

- No space constraints or color figure charges

- Immediate publication on acceptance

- Inclusion in PubMed, CAS, Scopus and Google Scholar

- Research which is freely available for redistribution 